\title{
Future Direction of DDDAS/InfoSymbiotics and Collaborations with Related Initiatives
}

\author{
Erik Blasch $^{1(\bowtie)}$, Robert Bohn ${ }^{2}$, Jahla Gato ${ }^{3}$, Edward McLarney ${ }^{4}$, Jasmin Ratchford ${ }^{5}$, \\ and Sonia Sachs 6 \\ 1 Air Force Office of Scientific Research, Arlington, VA 22203, USA \\ 2 National Institute of Standards and Technology, Gaithersburg, MD 20878, USA \\ 3 Australian Space Agency, Adelaide SA5000, Australia \\ 4 National Aeronautics and Space Administration, Hampton, VA 23666, USA \\ 5 Department of Homeland Security, Washington, DC 20002, USA \\ 6 Department of Energy, Washington, DC 20585, USA
}

\begin{abstract}
This panel brings together representatives from several funding agencies, who will address programmatic activities within their respective missions, which can support research and technology development in areas addressed in DDDAS2020 as well as those employing the DDDAS paradigm. Also, the panel will address potential for collaborations and synergism across agencies to support of basic and applied research and technology development in critical areas identified at the DDDAS2020 conference. Utilizing knowledge of recent trends, the panel will discuss programmatic changes, development efforts, and research opportunities across the federal sector, industry and academe, in the US and internationally.
\end{abstract}

Keywords: Programmatic activities $\cdot$ Technology development $\cdot$ Collaborations 